This item was submitted to Loughborough's Research Repository by the author.

Items in Figshare are protected by copyright, with all rights reserved, unless otherwise indicated.

\title{
One-pot synthesis of (R)-convolutamydine A involving in situ chiral organocatalyst formation
}

\section{PLEASE CITE THE PUBLISHED VERSION}

http://dx.doi.org/10.2478/asorg-2014-0002

\section{PUBLISHER}

De Gruyter Open / @ The Authors

\section{VERSION}

VoR (Version of Record)

\section{PUBLISHER STATEMENT}

This work is made available according to the conditions of the Creative Commons Attribution-NonCommercialNoDerivatives 3.0 Unported (CC BY-NC-ND 3.0) licence. Full details of this licence are available at: http://creativecommons.org/licenses/by-nc-nd/3.0/

\section{LICENCE}

CC BY-NC-ND 3.0

\section{REPOSITORY RECORD}

Wei, Shengwei, Bernard Schmid, Fliur Z. Macaev, Serghei N Curlat, Andrei V. Malkov, and Svetlana B. Tsogoeva. 2019. "One-pot Synthesis of (r)-convolutamydine A Involving in Situ Chiral Organocatalyst Formation". figshare. https://hdl.handle.net/2134/18842. 


\section{One-pot synthesis of $(R)$-convolutamydine $A$ involving in situ chiral organocatalyst formation}

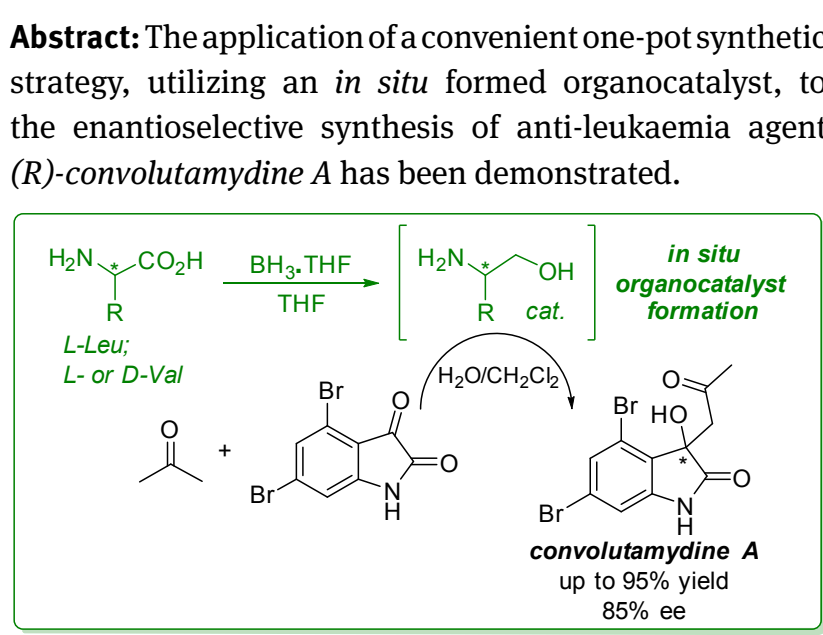

Keywords: chiral drug synthesis, organocatalysis, one-pot reactions, amino alcohols, reduction, aldol reaction

DOI 10.2478/asorg-2014-0002

Received October 20, 2014; accepted October 29, 2014

\section{Introduction}

The combination of one-pot multi-step operations and organocatalysis is an elegant, economically attractive method, which has gained considerable attention in modern synthetic chemistry [1-10]. Such synthesis usually relies on the use of organocatalysts prepared in advance [5-10].

Recently, we disclosed a new one-pot synthetic approach employing organocatalysts, prepared in situ via one-pot transformations and subsequently used for enantioselective synthesis of 1,2-amino alcohol derived chiral drugs [11]. According to our new approach, not only the target chiral compound, but also the organocatalyst required for its enantioselective formation can be synthesized in a one-pot procedure without intermediate isolation or purification steps, leading to the reduction of costs, saving of materials, time, effort and contributing further to the sustainability of the one-pot process.

To extend this concept further and to demonstrate its generality, we present here the application of our approach to the synthesis of convolutamydine A, which involves a two-step one-pot sequence, namely in situ organocatalyst formation (through reduction of amino acids $L$-Leu $\mathbf{1 a}$ or $L$-Val $\mathbf{1 b}$ to catalytically active amino alcohols) and addition of acetone to 4,6-dibromoisatin. (R)-Convolutamydine $A$ is a member of the oxindole subfamily, which exhibits a potent inhibitory activity on the differentiation of HL-60 human leukaemia cells [12].

The most convenient synthetic pathway towards enantiopure convolutamydine $A$ is the direct aldol reaction of acetone with 4,6-dibromoisatin. Few chiral organocatalysts have been developed for the preparation of convolutamydine $A$ using this aldol addition in moderate to high enantioselectivities (Scheme 1) [13-16].

Nonetheless, the reported synthetic methodologies towards (R)-convolutamydine A employ external organocatalysts (Scheme 1), prepared in advance which require isolation and purification. To meet the basic needs of the pharmaceutical chemistry, synthetic methods towards synthesis of chiral drugs must be simple, straightforward 

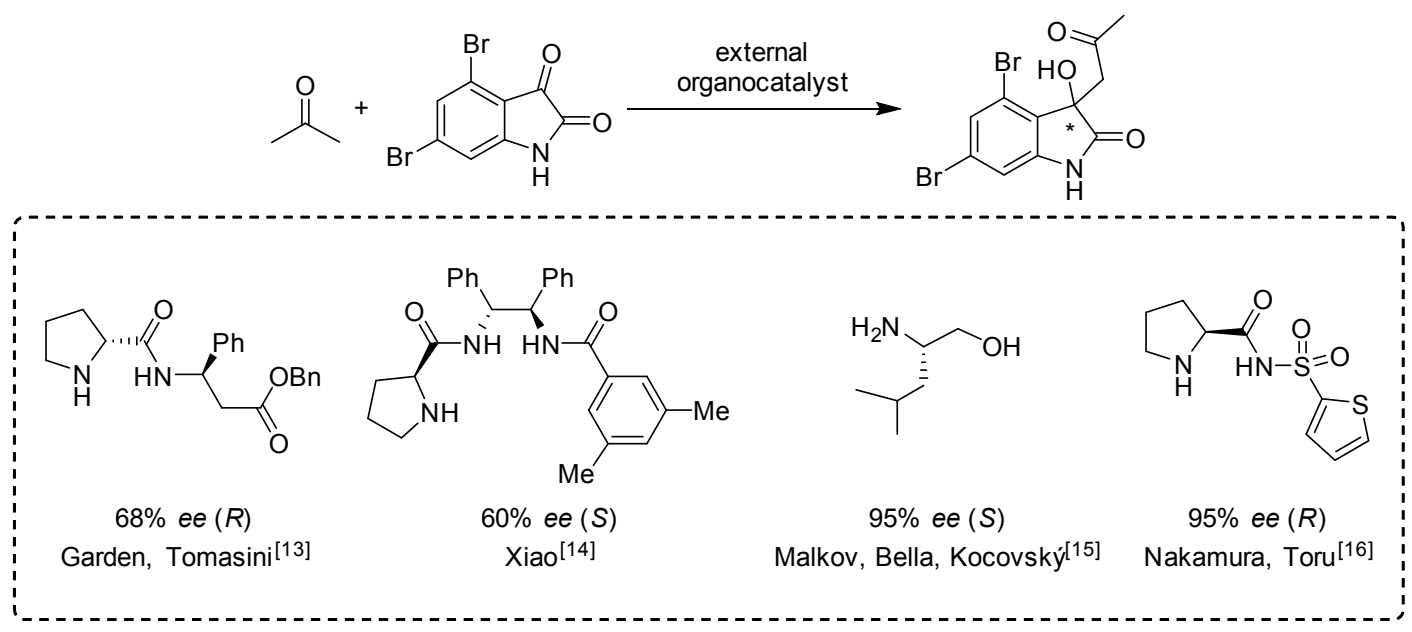

Scheme 1: Known chiral organocatalysts for the aldol reaction of acetone with 4,6-dibromoisatin.

and environmentally friendly [17]. Thus, finding a new facile and direct access to $(R)$-convolutamydine $A$ under mild reaction conditions and without intermediary workup and purification steps is highly attractive.

\section{Results and Discussion}

Following our previous work on organocatalytic aldol reactions $[18,19]$ and applying our expertise in the research fields of the organocatalytic construction of quaternary carbon centers[20-22] we decided to study the direct aldol reaction of acetone with 4,6-dibromoisatin.

Since amino alcohols $\mathbf{2 a}$ and $\mathbf{2 b}$ have already been reported by one of us as active external catalysts for the aldol addition of acetone to 4,6-dibromoisatin (entries 1 and 2, Table 1) [15], we were interested in exploring whether selected amino alcohols $\mathbf{2 c - 2 f}$ would perform as well as or even better than catalysts $\mathbf{2 a}$ and $\mathbf{2 b}$ in the same aldol addition. Reactions were run at room temperature in $\mathrm{CH}_{2} \mathrm{Cl}_{2}$ under conditions employing $20 \mathrm{~mol} \%$ of amino alcohols and water (100 mol\%) as an additive (Table 1). The use of (S)-proline derived catalyst $2 \mathrm{c}$ gave the $S$-configured product in high yield (93\%), but with only $4 \%$ ee (entry 3 ).

Interestingly, without water additive the carene derived catalyst $\mathbf{2 d}$ provides the $(S)$-convolutamydine $A$ with $44 \%$ yield and $51 \%$ ee (entry 4 ), while addition of $100 \mathrm{~mol} \%$ of water additive leads to the opposite enantiomer $(R)$-convolutamydine $A$ with $23 \%$ yield and $13 \%$ ee (entry 5 ). It seems that the enantioselectivity of the monoterpene based catalyst $\mathbf{2} \mathbf{d}$ can be reversed in the presence of water additive. Further studies are required to obtain more insight into the observed unusual switch in the enantioselectivity. Notably, in 2011 Wennemers and co-workers reported another intriguing example of reversal of enantioselectivity by changing the nature of the reaction medium in the tripeptide catalyzed aldol reaction of cyclohexanone and 4-nitrobenzaldehyde [23].

Next, application of two diastereoisomeric amino alcohols $2 \mathrm{e}$ and $\mathbf{2 f}$ gave the same $R$-configured product with similar results (entries 6 and 7, Table 1) regarding yields (90\% und 98\%, respectively) and enantioselectivities ( $77 \%$ ee and $78 \%$ ee, correspondingly). These observations demonstrate that the dominating influence on the absolute configuration of the resulting product convolutamydine $A$ resides in the stereogenic carbon center of the chiral catalyst adjacent to the amine group. These results also suggest the involvement of enamine activation mechanism.

Thus, under the same reaction conditions catalysts $\mathbf{2 c - 2 f}$, as alternatives of $\mathbf{2 a}$ and $\mathbf{2 b}$, promoted a less-stereoselective aldol transformation to afford the $S$ - or $R$-configured convolutamydine $A$ (entries 3-7 vs. entries 1 and 2, Table 1). Therefore, chiral amino alcohols $\mathbf{2 a}$ and $\mathbf{2 b}$ were selected as catalysts for further studies. Commercially available and cheap amino acids $L$-Leu 1a and $L$-Val $\mathbf{1 b}$ were used as starting materials for the in situ formation of selected chiral organocatalytic amino alcohols $L$-leucinol (2a) and $L$-valinol (2b).

For in situ generation of the corresponding vicinal amino alcohols (Table 2), we decided to apply previously optimized borane reduction of the amino acids employing $\mathrm{BH}_{3}$-THF (1.5 equiv.) in THF under reflux conditions [11]. No racemisation of the corresponding amino alcohols $\mathbf{2 a}$ and $\mathbf{2 b} / \mathbf{2} \mathbf{b}$ ' was observed under the selected reaction conditions.

Starting with $L$-Leu 1a and carrying out the proposed one-pot reaction without any additive, we isolated the product, convolutamydine $A$ in $30 \%$ yield in racemic 
Table 1: Synthesis of convolutamydine A using external chiral amino alcohols as catalysts.<smiles>CC(=O)OCCOC(=O)C1Nc2cc(Br)cc(Br)c2C1=O</smiles><smiles>CC(=O)CC1(O)C(=O)Nc2cc(Br)cc(Br)c21</smiles>

\begin{tabular}{|c|c|c|c|c|c|}
\hline Entry & Catalyst & $\begin{array}{l}\text { Water additive } \\
\text { (mol\%) }\end{array}$ & Time, $h^{a}$ & Yield (\%) & ee (\%) \\
\hline $1^{\mathrm{d}}$ & & 100 & 36 & 98 & $95(S)$ \\
\hline $2^{d}$ & & 100 & 36 & 84 & $95(S)$ \\
\hline 3 & & 100 & 48 & 93 & $4(S)$ \\
\hline 4 & & 0 & 36 & 44 & $51(S)^{\mathrm{e}}$ \\
\hline 5 & & 100 & 48 & 23 & $13(R)^{\mathrm{f}}$ \\
\hline 6 & & 100 & 144 & 90 & $77(R)$ \\
\hline 7 & & 100 & 48 & 98 & $78(R)$ \\
\hline
\end{tabular}

${ }^{\mathrm{a}}$ Reaction time required for complete conversion. ${ }^{\mathrm{b}}$ Yields of isolated products. ${ }^{\mathrm{c}}$ Determined by chiral phase HPLC analysis and compared with authentic racemic material. ${ }^{\mathrm{d}}$ Yields and ee-values have been previously reported $[15] .{ }^{\mathrm{e}}[\alpha]_{D}=+25.2(c 0.29, \mathrm{MeOH}) .{ }^{\mathrm{f}}[\alpha]_{D}=-6.36(c 0.015, \mathrm{MeOH})$.

form (entry 1, Table 2). Further optimisation of the twostep one-pot sequence revealed the necessity of presence of water as an additive in the aldol reaction step. Increasing the amount of water led to improved yield and enantioselectivity of (S)-convolutamydine $A$ (Table 2). We found that the addition of 5.0 equiv. of water resulted in $84 \%$ yield and $80 \%$ enantioselectivity (entry 4 , Table 2 ) after a relatively short reaction time.

Interestingly, larger amounts of water (e.g., 208.0 equiv.) resulted in decreased yield without loss of selectivity (65\%, 85\% ee, Table 2, entries 5-7).

Notably, a plausible transition state model was suggested for this aldol reaction catalyzed by external leucinol [15], which fits well with the experimental data, but does not include an explicit molecule of water. Therefore, it can be reasoned, that the presence of water in our one-pot reaction leads to an increase in the active catalyst $\mathbf{2 a}$ concentration, facilitating the enamine mechanism proposed previously [15]. Indeed, water might favour the release of the catalytically active free 1,2-amino 
alcohol 2a from the oxazaborolidine intermediate, which could be formed after the reduction step.

The decrease of reaction selectivity and yield at very high levels of water may be due to interference of water molecules with the hydrogen bond between the $\mathrm{OH}$-group

Table 2: Pre-optimisation of reaction conditions for one-pot synthesis of convolutamydine $\mathrm{A}$.

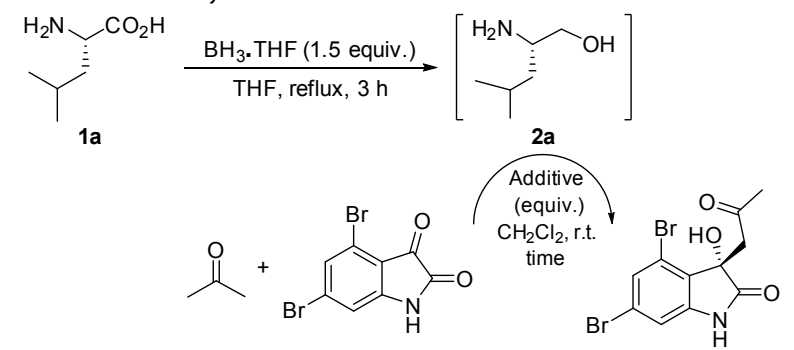

\begin{tabular}{lllll}
\hline Entry & $\begin{array}{l}\text { Additive } \\
\text { (equiv.) }\end{array}$ & Time, $\mathbf{h}$ & Yield (\%) $^{\mathrm{a}}$ & ee (\%) (S) $^{\mathrm{b}}$ \\
\hline 1 & - & 36 & 30 & $\mathrm{rac}$ \\
2 & $\mathrm{H}_{2} \mathrm{O}(1.0)$ & 24 & 70 & 75 \\
3 & $\mathrm{H}_{2} \mathrm{O}(3.0)$ & 36 & 60 & 79 \\
4 & $\mathrm{H}_{2} \mathrm{O}(5.0)$ & 18 & 84 & 80 \\
5 & $\mathrm{H}_{2} \mathrm{O}(7.0)$ & 18 & 79 & 85 \\
6 & $\mathrm{H}_{2} \mathrm{O}(9.0)$ & 18 & 75 & 80 \\
7 & $\mathrm{H}_{2} \mathrm{O}(208.0)$ & 18 & 65 & 85 \\
\hline
\end{tabular}

aYields of isolated products. ${ }^{b}$ Determined by chiral phase HPLC analysis and compared with authentic racemic material.

Table 3: One-pot organocatalyst / convolutamydine A sequential synthesis.

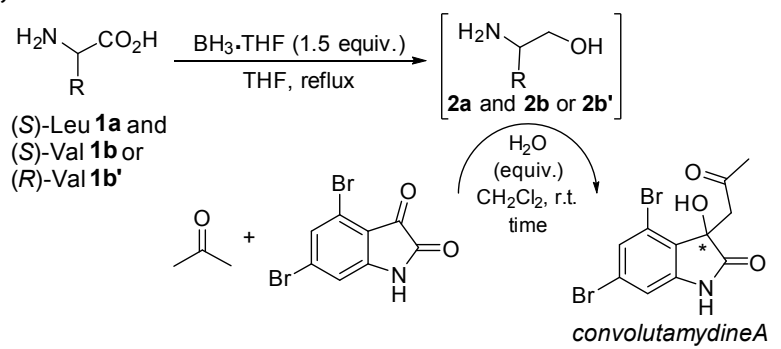

\begin{tabular}{|c|c|c|c|c|}
\hline Entry & Amino acid & Time, $\mathrm{h}$ & Yield (\%) ${ }^{a}$ & ee (\%) \\
\hline 1 & $(S)$-Leu $1 \mathrm{a}^{\mathrm{c}}$ & 18 & 84 & $80(S)$ \\
\hline 2 & $(S)$-Leu $1 a^{c}$ & 18 & 80 & $75(S)$ \\
\hline 3 & $(R)-$ Val $1 \mathbf{b}^{\mathbf{d}}$ & 18 & 95 & $70(R)$ \\
\hline 4 & $(S)-$ Val $\mathbf{1} \mathbf{b}^{d}$ & 18 & 82 & $77(S)$ \\
\hline 5 & $(R)-\mathrm{Val} \mathbf{1} \mathbf{b}^{\mathbf{d}}$ & 16 & 92 & $73(R)$ \\
\hline
\end{tabular}

aYields of isolated products. 'Determined by chiral phase HPLC analysis and compared with authentic racemic material. 'Reduction of $\mathbf{1 a}$ under reflux for $\mathbf{3} \mathrm{h}$. ${ }^{\mathrm{d} d}$ Reduction of $\mathbf{1 b}$ and $\mathbf{1} \mathbf{b}$ ' under reflux for $17 \mathrm{~h}$. of the catalyst and the keto group of dibromoisatin in the transition state. This agrees with the decrease of selectivity observed in protic solvents like methanol [15].

Based on the pre-optimisation with $L$-leucine shown in Table 2, we next studied the reproducibility of the twostep one-pot synthesis using two different amino acids, namely $L$-leucine $\mathbf{1 a}$ and $D$-valine $\mathbf{1 b}$ '. In general, $L$-amino acids preferentially afford the (S)-enantiomer (entries 1,2 and 4, Table 3), while $D$-amino acids (e.g. (R)-1b', entries 3 and 5) gave the desired (R)-configured convolutamydine $A$.

Consequently, we optimized the synthesis of the natural product convolutamydine $A$ in a one-pot reaction over two steps. We obtained the product in reproducible high yields and good ee-values (80-95\% yields and 73-80\% ees, entries 1-5, Table 3). Leucine 1a gave better ee-values than valine $\mathbf{1 b}$. Further improvement of the ee-values of convolutamydine $A$ with respect to the value determined directly from the crude reaction mixture should be possible by means of crystallization [15].

\section{Conclusions}

In summary, the synthesis of an anti-leukaemia agent convolutamydine A via a two-step one-pot transformation involving in situ chiral organocatalyst formation from commercially available inexpensive starting materials $(\alpha$-amino acids) has been investigated. The advantages of such one-pot reactions are the reduction of work-up and purification steps, resulting in lower costs, material and labor input, which makes the multi-step sequential synthesis even more efficient, atom economical and environmentally friendly.

\section{Experimental Section}

\subsection{General}

Solvents were purified by standard procedures and distilled prior to use. Reagents purchased from commercial sources were used without further purification. TLC chromatography was performed on pre-coated aluminium silica gel ALUGRAM ${ }^{\circledR}$ SIL G/UV254 plates (Macherey-Nagel GmbH\&Co.). Flash chromatography was performed using silica gel Merck 60 (particle size 0.040-0.063 mm). ${ }^{1} \mathrm{H}$ NMR and ${ }^{13} \mathrm{C}$ NMR spectra were recorded on Bruker Avance 400 NMR spectrometer using the solvent as internal standard. The enantiomeric excess of products was determined by chiral HPLC analysis (using chiral column: Daicel Chiralpak IA) in comparison with authentic 
racemic material. HPLC measurements were performed using Agilent Technologies 1200 Series equipment. A PerkinElmer 341 polarimeter was used for optical rotation measurements.

\subsection{One-pot procedure for the synthesis of (R)-convolutamydine A:}

To a stirred solution of $D$-Valine ( $32 \mathrm{mg}, 0.27 \mathrm{mmol}$ ) in dry THF $(0.41 \mathrm{~mL})$ at $0^{\circ} \mathrm{C}$, was added $\mathrm{BH}_{3} \cdot \mathrm{THF}(0.41 \mathrm{~mL}, 1.0 \mathrm{M}$ in THF) via syringe. The reaction mixture was then stirred for $17 \mathrm{~h}$ under reflux. The conversion was followed by TLC. The reaction mixture was cooled to room temperature and $\mathrm{CH}_{2} \mathrm{Cl}_{2}(6.57 \mathrm{~mL})$ and water $(5$ equiv., $0.086 \mathrm{~mL})$ were added slowly, After 1 minute, 4,6-dibromoisatin (1 equiv., $0.96 \mathrm{mmol}, 290.73 \mathrm{mg}$ ) and acetone (30 equiv., $28.2 \mathrm{mmol}$, $2.11 \mathrm{~mL}$ ) were then added. The reaction mixture was stirred at room temperature for additional $16 \mathrm{~h}$, and was then washed with water and dried over $\mathrm{Na}_{2} \mathrm{SO}_{4}$. The organic solvents were removed under reduced pressure and the residue was purified by flash chromatography on $\mathrm{SiO}_{2}$ (ethyl acetate / petrolether 1:1) to give ( $R$ )-convolutamydine A as a white solid (317 mg, 92\% yield, $73 \%$ ee).

The enantiomeric excess was determined by chiral HPLC analysis (Daicel Chiralpak IA column, $\lambda=210 \mathrm{~nm}$, mobile phase n-hexane/iPrOH 85:15, flow $0.95 \mathrm{~mL} / \mathrm{min}$ ). $[\alpha]_{\mathrm{D}}^{25}+43.9(c$ 0.33, MeOH) [lit. [15] +48.9 (c 0.33, MeOH)]; ${ }^{1} \mathrm{H}$ NMR (300 MHz, DMSO-d6): $\delta=2.03$ (s, 3H), 3.12 (d, $J=$ $16.8 \mathrm{~Hz}, 1 \mathrm{H}$ ), $3.76(\mathrm{~d}, J=17.7 \mathrm{~Hz}, 1 \mathrm{H}), 6.22$ (br s, $1 \mathrm{H}, \mathrm{OH})$, 6.94 (d, $J=1.2 \mathrm{~Hz}, 1 \mathrm{H}), 7.28$ (d, $J=1.2 \mathrm{~Hz}, 1 \mathrm{H}), 10.64$ (s, 1H) ppm; ${ }^{13} \mathrm{C}$ NMR (75 MHz, DMSO-d6): $\delta=205.3,177.3,146.4$, $128.7,126.7,122.4,119.6,111.8,73.7,48.3,30.0 \mathrm{ppm} ; \mathrm{IR}_{\text {(neat) }}: \mathrm{v}$ $=3313,3226,1703,1605,1578,1432,1358,1317,1166,1076$, $845,677 \mathrm{~cm}^{-1}$. MS (MALDI) spectrum showed molecular ions $[\mathrm{M}+\mathrm{Na}]^{+}$at $\mathrm{m} / \mathrm{z} 384,386$ and 388 respectively $[\mathrm{M}+\mathrm{K}]^{+}$ at $\mathrm{m} / \mathrm{z} 400,402$ and 404 in the ratio 1:2:1.

Acknowledgments: S.B.T is grateful to the Interdisciplinary Center for Molecular Materials (ICMM), Erlangen Catalysis Resource Center (ECRC) and Deutsche Forschungsgemeinschaft (DFG) for research support. S.B.T. and F.Z.M. acknowledge financial support from the BMBF and AȘM (bilateral BMBF-AȘM project Ref. № MDA 08/010 and № 09.820.05.08 GF).

\section{References}

[1] Nicolaou, K.C., Montagnon, T., Snyder, S.A., Tandem reactions, cascade sequences, and biomimetic strategies in total synthesis, Chem. Commun., 2003, 551-564.
[2] Tietze, L.F., Brasche, G., Gericke, K. M., Domino Reactions in Organic Synthesis, Wiley-VCH, Weinheim, 2006.

[3] Tietze, L. F., Domino Reactions: Concepts for Efficient Organic Synthesis, Wiley-VCH, Weinheim, 2014.

[4] Nicolaou, K.C., Edmonds, D.J., Bulger, P. G., Cascade Reactions in Total Synthesis, Angew. Chem. Int. Ed., 2006, 45, 7134-7186.

[5] Enders, D., Grondal, C., Hüttl, M.R.M., Asymmetric Organocatalytic Domino Reactions, Angew. Chem. Int. Ed., 2007, 46, 1570-1581.

[6] Vaxelaire, C., Winter, P., Christmann, M., One-Pot Reactions Accelerate the Synthesis of Active Pharmaceutical Ingredients, Angew. Chem. Int. Ed., 2011, 50, 3605-3607.

[7] Albrecht, t., Jiang, H., Jørgensen, K. A., A Simple Recipe for Sophisticated Cocktails: Organocatalytic One-Pot ReactionsConcept, Nomenclature, and Future Perspectives, Angew. Chem. Int. Ed., 2011, 50, 8492-8509 and references therein.

[8] Weiß, K., Wei, S.-W., Tsogoeva, S. B., Novel one-pot process for the synthesis of 1,3-thiazoles via organocatalysed epoxidation of nitro-olefins, Org. Biomol. Chem., 2011, 9, 3457-3461.

[9] Wei, S.-W., Weiß, K. M., Tsogoeva, S. B., Convenient One-Pot Two-Step Synthesis of 1,3-Thiazoles via Organocatalyzed Epoxidation of Nitroolefins, Synthesis, 2012, 44, 3441-3446.

[10] Ibrahim, M. M.; Grau, D., Hampel, F., Tsogoeva,S.B., $\alpha$-Nitro Epoxides in Organic Synthesis: Development of a One-Pot Organocatalytic Strategy for the Synthesis of Quinoxalines, Eur. J. Org. Chem., 2014, 1401-1405.

[11] Wei, S.-W., Messerer, R., Tsogoeva, S.B., Asymmetric Synthesis of $\beta$-Adrenergic Blockers through Multistep One-Pot Transformations Involving In Situ Chiral Organocatalyst Formation, Chem. Eur. J., 2011, 17, 14380-14384.

[12] Kamano, Y., Zang, H., Ichihara, Y., Kizu, H., Komiyama, K., Pettit, G.R., Convolutamydine A, a novel bioactive hydroxyoxindole alkaloid from marine bryozoan Amathia convoluta, Tetrahedron Lett., 1995, 36, 2783-2784.

[13] Luppi, G., Monari, M., Corrêa, R. J., Violante, F. de A., Pinto, A. C., Kaptein, B., Broxterman, Q. B., Garden, S. J., Tomasini, C., The first total synthesis of $(R)$-convolutamydine A, Tetrahedron, 2006, 62, 12017-12024.

[14] Chen, J.-R., Liu, X.-P., Zhu, X.-Y., Li, L., Qiao, Y.-F., Xiao, W.-J., Zhang, J.-M. Organocatalytic asymmetric aldol reaction of ketones with isatins: straightforward stereoselective synthesis of 3-alkyl-3-hydroxyindolin-2-ones, Tetrahedron, 2007, 63, 10437-10444.

[15] Malkov, A.V., Kabeshov, M. A., Bella, M., Kysilka, O., Malyshev, D.A., Pluháčková, K., Kočovský, P., Vicinal Amino Alcohols as Organocatalysts in Asymmetric Cross-Aldol Reaction of Ketones: Application in the Synthesis of Convolutamydine A, Org. Lett., 2007, 9, 5473-5476.

[16] Nakamura, S., Hara, N., Nakashima, H., Kubo, K., Shibata, N., Toru, T., Enantioselective Synthesis of ( $R$ )-Convolutamydine A with New N-Heteroarylsulfonylprolinamides, Chem. Eur. J., 2008, 14, 8079-8081.

[17] Held, F. E., Wei, S., Eder, K., Tsogoeva, S. B., One-pot route to $\beta$-adrenergic blockers via enantioselective organocatalysed epoxidation of terminal alkenes as a key step, RSC Adv., 2014, 4, 32796-32801.

[18] Tsogoeva, S. B., Wei, S.-W., (S)-Histidine-based dipeptides as organic catalysts for direct asymmetric aldol reactions, Tetrahedron: Asymmetry, 2005, 16, 1947-1951. 
[19] Tsogoeva, S. B., Jagtap, S. B., Ardemasova, Z. A., 4-trans-Amino-proline based di- and tetrapeptides as organic catalysts for asymmetric $\mathrm{C}-\mathrm{C}$ bond formation reactions, Tetrahedron: Asymmetry, 2006, 17, 989-992.

[20] Baudequin, C., Zamfir, A., Tsogoeva, S. B., Highly enantioselective organocatalytic formation of a quaternary carbon center via chiral Brønsted acid catalyzed self-coupling of enamides, Chem. Commun., 2008, 4637-4639.

[21] Freund, M. H., Tsogoeva, S. B., L-Proline-Catalyzed Asymmetric Michael Addition of 2-Oxindoles to Enones: A Convenient
Access to Oxindoles with a Quaternary Stereocenter, Synlett, 2011, 503-507.

[22] Reiter, C., López, S., Schmid, B., Neiss, C., Görling, A., Tsogoeva. S. B., Michael Addition of $\mathrm{N}$-Unprotected 2-Oxindoles to Nitrostyrene Catalyzed by Bifunctional Tertiary Amines: Crucial Role of Dispersion Interactions, ChemCatChem, 2014, 6, 1324-1332.

[23] Messerer M., Wennemers H., Reversing the enantioselectivity of a peptidic catalyst by changing the solvent, Synlett, 2011, 499-502. 